\title{
A percepção de secretários municipais de saúde sobre a gestão do trabalho e da educação na rede pública do Sistema Único de Saúde (SUS) Perception of municipal health secretaries of the management of work and education in the public network of the Brazilian Unified Health System (SUS)
}

\author{
Sônia Cristina Vermelho \\ Universidade Federal do Rio de Janeiro. Núcleo de Tecnologia \\ Educacional para Saúde. Rio de Janeiro, RJ, Brasil. \\ E-mail: cristina.vermelho®gmail.com

\section{Gustavo Figueiredo} \\ Universidade Federal do Rio de Janeiro. Núcleo de Tecnologia \\ Educacional para Saúde. Rio de Janeiro, RJ, Brasil. \\ E-mail: gfigueiredo.ufrjळgmail.com
}

\section{Correspondência}

Sônia Cristina Vermelho

Rua São Salvador, 59, ap. I.310, Flamengo.

Rio de Janeiro, RJ, Brasil. CEP 22231-130.

\section{Resumo}

O artigo apresenta resultados de pesquisa empírica com secretários municipais de saúde de microrregião do Paraná, e tem por objetivo analisar os mecanismos da gestão do trabalho e da educação em saúde durante a implantação das redes de atenção básica na região. Utilizamos método integrado quali-quantitativo com questionário e entrevistas semiestruturadas realizadas com 24 gestores. 0 material foi transcrito, categorizado e analisado com o método de análise de conteúdo temático. Os resultados indicaram concepção reduzida quanto à gestão do trabalho e da educação, entendidos como processos autônomos entre si, limitada à oferta de cursos, sem uma compreensão das possibilidades de gestão integrada de educação e trabalho. Prevalece uma visão de gestão do setor público baseada no gerencialismo e na performatividade, consideradas tecnologias políticas neoliberais. Resultados apontam que, na percepção dos secretários municipais de saúde, as principais dificuldades para a implementação de ações educativas são: logística tempo/espaço para articular trabalho e formação, falta de interesse dos trabalhadores, determinantes externos de natureza política/jurídica. Entre os incentivos para a formação dos profissionais, surge majoritariamente a questão financeira, o que em momentos de crise econômica é preocupante, pois pode revelar paralisia nessas práticas de formação profissional. É preciso considerar, ainda, a existência de lacuna entre debate teórico no campo da educação em saúde e a discrepante realidade encontrada nesses municípios. Conclui-se indicando que, apesar de haver consenso da importância da educação em saúde para a qualidade da atenção e organização do processo de trabalho nos serviços de 
saúde, existe ainda longo caminho a percorrer para aprimorar a gestão pública dessas ações no Sistema Único de Saúde.

Palavras-chave: Educação em Saúde; Trabalho em Saúde; Gestão; Saúde Pública.

\section{Abstract}

The article presents empirical research results with municipal health secretaries of a micro-region of Paraná. We aim to analyze the mechanisms of work and health education management during the implementation of basic care networks in the region. We used an integrated qualitativequantitative method, with a questionnaire and semi-structured interviews with 24 managers. The material was transcribed, categorized and analyzed using the thematic content analysis method. The results indicated a reduced conception of work and education management, understood as processes independent from each other, limited to the offer of courses, without an understanding of the possibilities of an integrated management. There is a prevailing view of public sector management based on managerialism and on performativity, which are considered neoliberal political technologies. Our results allow us to affirm that in the perception of the municipal health secretaries, the main difficulties for the implementation of educational actions are: the time-space logistics to articulate work and training, the workers' lack of interest, and political and legal external determinants. Among the incentives for the training of professionals, the financial issue stands out, which at times of economic crisis is worrying, as it may reveal a paralysis in these professional training practices. It is also necessary to consider the existence of a huge gap between the theoretical debate in the health education field and the discrepant reality found in these municipalities. Finally, we concluded that although there is a consensus on the importance of health education for the quality of care and for the organization of the work process in health services, there is still a long way to improve the management of these actions in the Brazilian Unified Health System.

Keywords: Health Education; Health Work; Management; Public Health.

\section{Introdução}

Este artigo apresenta os resultados de pesquisa empírica quanti-qualitativa realizada com gestores municipais de saúde numa microrregião do noroeste do Paraná, sobre o tema da formação profissional em saúde. 0 estudo analisa dados do questionário exploratório e o conteúdo das entrevistas a partir de dois eixos de reflexão sobre o processo de gestão do trabalho e da educação em saúde: eixo 1 - dificuldades e limitações encontradas; eixo 2 - estímulos, incentivos e motivação. 0 artigo está organizado no seguinte modo: inicia com uma contextualização da microrregião estudada, apresenta dados sobre o número de profissionais em relação à densidade populacional; em seguida, faz uma discussão teórica sobre a formação de recursos humanos para o SUS, articulando as categorias trabalho e educação; então se relata a metodologia da pesquisa, discute os resultados encontrados e faz um esforço de sintetizar as principais questões em torno deste debate nas conclusões indicando desafios, construindo perspectivas de ação e sugerindo possibilidades para novas pesquisas.

\section{Contexto da pesquisa}

A pesquisa foi financiada pelo edital "Programa de Pesquisa para o Sistema Único de Saúde: Gestão Compartilhada em Saúde PPSUS - Edição 2012" com o título "Levantamento e avaliação das Redes de Atenção à Saúde da região de atuação do Consórcio Público Intermunicipal de Saúde do Setentrião Paranaense (Cisamusep)" na linha Temática "Indicadores e modelos de avaliação da estruturação, desempenho e resultados das Redes de Atenção à Saúde”. O recorte deste artigo se propõe a analisar a microrregião em termos de formação dos profissionais vinculados às Redes de Atenção.

Foi um estudo transversal, descritivo e de abordagem quanti-qualitativa, que utilizou dois tipos de instrumentos: questionário estruturado com profissionais de saúde e entrevista com os secretários de saúde dos municípios da microrregião.

A microrregião estudada está situada na região noroeste do estado, com os municípios organizados na Associação dos Municípios do Setentrião Paranaense 


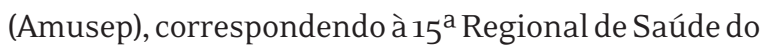
Paraná. A gestão do SUS é realizada pelos entes federativos e mais o Consórcio Intermunicipal de Saúde, o Cisamusep, que faz a gestão compartilhada para atender as especialidades; com isso, as prefeituras dão prioridade ao atendimento médico na atenção básica e as especialidades são geridas pelo Consórcio.

A microrregião é composta por trinta cidades, sendo que a menor possui uma população de 1.898 habitantes e a maior mais de 350 mil habitantes. 0 total da população é de mais de 750 mil habitantes. Conforme Scheffer (2015) o número de profissionais para atender a essa população, incluindo os servidores públicos e profissionais conveniados, é próximo de 4 mil de enfermagem, incluídos os auxiliares e técnicos; mais de 4 mil médicos, sendo mais de 1.200 para a ESF; e mais de 1.500 de outras áreas, totalizando mais de 10 mil profissionais. A microrregião possui uma relação de 15 profissionais para cada grupo de 1000 habitantes. Quanto aos médicos, incluindo as especialidades, a relação é de 6 médicos para cada 1000 habitantes e, especificamente em relação aos médicos do programa Estratégia de Saúde da Família (ESF), a relação é 1,8 médicos para cada 1.000 habitantes. A relação de médicos nesta microrregião ficou bem acima da média brasileira, que é de 1,54 médicos para cada 1.ooo habitantes; na América Latina somente Cuba se aproxima dessa relação (5,9 médicos/1.ooo hab).

A partir desse contexto inicial, será discutida a problemática da organização do processo de trabalho e da formação em serviço dos profissionais em saúde.

\section{Formação de recursos humanos para - Sistema Único de Saúde}

Um dos principais desafios no processo de implantação do Sistema Único de Saúde (SUS) se constitui na política de recursos humanos para a qualificação da força de trabalho com vistas à construção do modelo de atenção integral à saúde. Para enfrentar esse desafio é preciso desenvolver um conjunto de ações que proporcione uma ampliação da concepção do processo de trabalho e de educação em saúde. Dentre essas ações, talvez a mais potente seja estimular a reflexão crítica sobre o próprio processo de trabalho das equipes, reconhecendo o potencial formativo do trabalho e incorporando-o como eixo orientador da formação para os trabalhadores do SUS.

O sistema de saúde brasileiro tem uma enorme dificuldade em produzir mudanças nas práticas de saúde em consonância com os avanços teóricos da área de saúde coletiva. Contudo, são inegáveis os esforços que vêm sendo empreendidos com processos de formação e qualificação profissional no Sistema Único de Saúde, todavia, sem atingir a transformação desejada nas práticas de saúde. É provável que um dos principais motivos desse problema seja o fato de que os processos educacionais, na maioria das vezes, priorizam os conteúdos e a formação técnica individual dos profissionais, sem com isso conseguir impactar no trabalho das equipes e, muito menos, mudar o cotidiano dos serviços de saúde.

De acordo com Casotti (2009), desde os anos 1960, existe uma grande preocupação com o tema da educação profissional na área da saúde, inclusive com a criação de órgãos nas universidades, tal como o Nutes-Clates/UFRJ, e também grupos de desenvolvimento tecnológico e pesquisa na Fundação Oswaldo Cruz, iniciativas da Universidade Federal da Bahia, da Universidade Federal de Minas Gerais, da Unicamp e da Universidade Federal do Rio Grande do Sul; além de secretarias e departamentos no Ministério da Saúde, passando pelas associações de articulação interinstitucional, como a Rede Unida e o Finepas. Também os programas VER-SUS, AprenderSUS, Pró-Saúde, Política Nacional de Educação Permanente em Saúde, o Promed, Provab e o eixo de formação do Programa Mais Médicos. Constituem-se em ações governamentais com o objetivo de causar um reordenamento tanto das políticas de saúde como de educação, visando qualificar o profissional de saúde e aprimorar sua atuação no SUS (Casotti, 2009).

Outra ação importante e de envergadura foi a criação da Universidade Aberta do SUS (UNA-SUS), em que, a despeito das críticas anteriores, acabou por induzir a adesão das universidades à rede e mobilizar a cooperação entre as instituições formadoras, aproximando diferentes instituições para lidar com a problemática da educação/formação (Carvalho, 2016).

Porém, apesar de todos esses esforços, a consolidação do SUS ainda sofre com a formação dos profissionais em saúde. Pensamos que essas dificuldades 
se alinhem à própria definição da Educação Permanente em Saúde, que é resultado da complexidade em se articular dois conceitos polissêmicos: educação e trabalho. As discussões sobre esse tema colocam a categoria processo de trabalho na centralidade dos processos educacionais, o que torna necessário que os atores locais adotem a reflexão sobre o fazer como fonte de aprendizado. Para tanto, surgem as dificuldades inerentes a todo processo coletivo e democrático, impondo a necessidade de novos pactos políticos concernentes à gestão e novos parâmetros para as relações interpessoais entre todos os sujeitos envolvidos (gestores, trabalhadores de saúde, população atendida, movimentos sociais e instituições de formação).

Nesse sentido, talvez a maior dificuldade resida exatamente em transformar a cultura organizacional de serviços, em que, para resolver os principais problemas que surgem nas equipes e nos serviços de saúde, é necessário pensar as diferentes relações sociais que se estabelecem entre os sujeitos em determinado modelo assistencial e um reposicionamento dos atores frente ao seu trabalho (Figueiredo; Brito; Botazzo, 2003).

Fundamentada na perspectiva da Organização Pan-Americana de Saúde (Opas), as diferentes concepções que tiveram êxito em estruturar a cultura dos serviços de saúde trazem implícitas concepções do trabalho, do trabalhador, das relações de poder, da participação, da natureza dos contratos de trabalho formais e informais, que predeterminam os espaços permitidos, os estilos educacionais, os conteúdos e as características das demandas que especificamente podem ser feitas à Educação Permanente em Saúde (Rovere, 1994).

É possível, portanto, considerar que um dos maiores desafios para a corrente crítica da educação no campo da saúde seria ampliar os objetivos da formação profissional para além dos conteúdos e da transmissão de informação técnico-científica, incorporando também nos processos educacionais na área da saúde as dimensões ética e política como base do exercício profissional (Freire, 2014; Gadotti, 2012). Encontramos, assim, um campo fértil de desenvolvimento para a articulação dos projetos de integração ensino-serviço, o que pode reforçar a compreensão e a prática da formação como socialização profissional.
Ao refletir sobre a formação de sujeitos com qualidades específicas para a realidade cultural e socioeconômica brasileira é preciso construir uma problematização do processo de trabalho pelo próprio sujeito do trabalho, dando voz aos seus questionamentos e apoiando a reorganização das práticas em nível local. Segundo Teixeira e Paim (1996), esse processo político poderá ensejar o aparecimento de segmentos inovadores e novas lideranças no estabelecimento de diretrizes para a saúde. Como afirma Giroux (1986), a consciência e a experiência são o ponto de referência para o desenvolvimento de práticas críticas e contextualizadas de educação permanente. Ao incorporarem no campo de significados da equipe uma reflexão sobre as relações de poder na sociedade, onde as doenças são geradas, e proporem simultaneamente o reordenamento do modelo de atenção em saúde, os atores locais estariam iniciando o processo de construção de um novo paradigma para a saúde pública (Campos; Cunha; Figueiredo, 2013).

Para a implementação de um processo de Educação Permanente em Saúde com esse viés crítico, seria necessário favorecer o desenvolvimento de uma nova consciência social, baseada na compreensão dos cidadãos como os principais sujeitos do processo de mudança das sociedades. A proposição de novas práticas de saúde como tentativa de resposta a contradições reais da prática como é hoje, só pode ser buscada no reconhecimento das próprias contradições, no interior das situações concretas em que são realizadas, bem como na transformação da escala de valores, com o resgate do humanismo e o desenvolvimento da ética na saúde (Portillo; Belaciano, 1994). É nesse sentido que as práticas de educação permanente podem constituir-se também como importante eixo de estruturação para a construção de ambientes de aprendizagem. Elegendo o próprio processo de trabalho como objeto de reflexão para o desenvolvimento de uma consciência crítica.

\section{Gerencialismo e performatividade: tecnologias neoliberais para gestão do setor público}

O conceito de mercantilização é empregado por Ball no contexto do processo de reformulação do 
setor público ao final do século XX, o qual passa a integrar e a ser gerido pela lógica do mercado. Esse movimento de cunho neoliberal traz um enfraquecimento do Estado, dando total liberdade para atuação do setor privado no controle dos processos sociais (Ball; Maguire; Braun, 2012). Para dar conta do neoliberalismo de fato existente, mudanças estão ocorrendo no papel do Estado, que na sua definição de limitador de mercado passa também à de criador de condições nas quais o próprio mercado pode florescer e expandir. Essa dualidade de regulação e de facilitação é expressa e colocada em prática por meio de metagovernança que se caracteriza como a organização das condições de governança em seu sentido mais amplo representando um deslocamento na organização e nas práticas do Estado, comumente referida como uma mudança de governo para governança (Ball; Maguire; Braun, 2012).

No Brasil, essas reformas, promovidas principalmente a partir de meados da década de 1990, foram marcadas pela intervenção consentida e pela introdução de novos mecanismos de controle, regulação social e pela redefinição do ordenamento constitucional legal, a partir da Constituição Federal de 1988. O discurso trazia o objetivo da "construção e o fortalecimento da cidadania e o aumento das possibilidades de emprego", alardeando-se a construção de um "novo cidadão brasileiro". Para isso, exigiu-se intensa mudança institucional e a construção de uma nova organização social baseada num "novo paradigma de Estado, cuja racionalidade encontrava-se vazada por valores mercantis" (Ball et al., 2013).

No campo da gestão de recursos humanos, conceitos de setores privados trazem para instituições públicas novos paradigmas que "relacionam mercados com gestão, com performatividade e com transformações na natureza do próprio Estado" (Ball, 2001, p. 104), ou seja, um "pacote de reformas" que visam estabelecer teoricamente relações de parceria entre o público e o privado. Diante dessas relações de parceria entre o público e o privado, uma das formas de garantir essa nova cultura é utilizando as novas tecnologias políticas:

O gerencialismo e a performatividade. 0 profissional torna-se um sujeito inseguro a ponto de buscar incessantemente um desempenho de perfeição na instituição a que pertence, que [...] jamais podem ser alcançados; pela ilusão que se desfaz de uma finalidade a ser modificada (Ball, 2005, p. 546).

O gerencialismo e a performatividade são termos definidos por Ball como tecnologias políticas utilizadas na modernidade a fim de criar novas culturas que têm permeado as instituições públicas com novos valores e sentimentos oriundos de empresas privadas. Essas tecnologias políticas são também definidas como pedagogias invisíveis que são utilizadas para imbuir o profissional de uma responsabilidade na qual suas tarefas devem ser cada vez melhores (Ball, 2005).

A performatividade vai ao encontro das relações de poder entre os atores do setor saúde consolidando uma visão produtiva baseada nas noções da mercantilização. Ball entende performatividade como "Uma tecnologia, uma cultura e um método de regulamentação que emprega julgamentos, comparações e demonstrações como meios de controle, atrito e mudança" (Ball, 2005, p. 543).

O gerencialismo tem sido um dos canais de entrada para reforma dos serviços públicos, com a penetração do setor privado e importante vetor para desestruturar a ética profissional que prevalecia nas instituições sócias públicas. Esses métodos de regulamentação estão claramente ressaltados nos sistemas de avaliações, ranking, premiações e uma série de fatores que modificam e modelam os processos de interpretações e traduções (Ball; Maguire; Braun, 2012).

A performatividade é, portanto, uma estratégia de controle em que o emprego de regras diverge dos anseios éticos profissionais, pois estes exigem uma remodelação do profissional de acordo com os objetivos da organização onde estão inseridos. Sendo assim, as tecnologias políticas têm a pretensão de fazer com que os profissionais pensem, sintam e atuem de acordo com as demandas da instituição, ou seja, elas têm a capacidade de remodelar à sua imagem as organizações que monitoram (Ball, 2005).

Na área da saúde, temos observado cada vez mais o uso dessas tecnologias políticas como instrumentos para a gestão de recursos humanos e do processo de trabalho. A internalização dessas 
práticas por secretários de saúde e profissionais acaba por estabelecer um modelo de gestão pouco participativo e inspirado na lógica da produtividade e da performance individual.

\section{Metodologia}

Este estudo foi organizado com base numa metodologia com enfoque integrado quanti-qualitativo (Anguera, 2004, 2010; Sampieri; Collado; Lucio, 2006). A coleta de dados ocorreu entre os meses de agosto de 2014 a março de 2015, após a aprovação do projeto pelo Comitê de Ética em Pesquisa, parecer $n^{0}$ 66.312. Declaramos que não há conflito de interesses dos autores.

A coleta de dados nos 30 municípios por meio de questionários exploratórios se deu numa amostra qualificada; na etapa qualitativa foi feita entrevista semiestruturada com os secretários municipais de saúde. Para garantir o anonimato e preservar a identidade dos 24 gestores entrevistados, os nomes dos municípios foram codificados (Mx), sendo $\mathrm{M}$ uma letra comum a todos os municípios e $\mathrm{x}$ uma numeração sequencial de 1 a 24, sem critério de escolha no sequenciamento.

Os dados foram tratados no software Atlas.ti, versão 6.o, seguindo a metodologia da análise de conteúdo (Bardin, 1977). Com base naqueles excertos, organizamos os resultados a partir de dois eixos transversais de análise: 1) dificuldades; e 2) incentivos ao processo de gestão do trabalho e da educação em saúde.

Aprofundando a complexidade da análise, foi possível a partir do mapeamento inicial, identificar na análise do conteúdo, quais as falas dos gestores que poderiam ser agrupadas. Por fim, decidimos estabelecer a análise a partir de seis categorias construídas a partir do conteúdo das entrevistas, a saber: 1) determinantes políticos e jurídicos da administração pública; 2) tensão entre a liberação de tempo do trabalho e o tempo necessário para a formação; 3) incentivos financeiros e valorização na carreira; 4) dimensão individual subjetiva do profissional de saúde; 5) acesso à formação: distância geográfica e deslocamento; 6) demandas por formação a partir do processo de trabalho em equipe.

Além das entrevistas, foram organizados os dados quantitativos coletados por meio do ques- tionário exploratório inicial. Os dados quantitativos apoiam em alguns aspectos nossa análise, buscando a construção de um texto integrado e claro com objetivo de contribuir para a discussão teórico-prática da problemática que envolve as relações entre as categorias trabalho e educação no contexto do SUS.

\section{Resultados}

A amostra foi composta de 339 respondentes oriundos de nove municípios; os sujeitos atuam em 46 unidades públicas de saúde, sendo $81 \%$ do sexo feminino e $19 \%$ masculino.

Da amostra de profissionais, em relação à carga horária de trabalho semanal contratual, a ampla maioria possui contrato de 40 horas (66,1\%), e 7,2\% com 20 horas ou menos. Em relação ao tempo de trabalho na profissão atual, a média foi de 9,8 , desvio-padrão 8,78; quanto ao tempo de trabalho no setor público, a média foi de 9,o, desvio-padrão 7,46; e o tempo de trabalho na unidade a média foi de 5,77 e desvio-padrão 5,76. Quanto ao vínculo, 50,8\% são estatutários, 37,7\% celetistas e 11,6\% prestadores de serviço. Notemos que o perfil dos profissionais na região é de que possuem certa experiência na saúde e, majoritariamente, no setor público; dentre o tempo de atuação, muitos permaneceram na mesma unidade a maior parte do tempo de exercício profissional, metade com contrato de trabalho de servidor público.

Quanto ao conhecimento do plano de carreira dos municípios, 46,8\% tinham conhecimento do plano, desses $23 \%$ afirmou que no plano de carreiras havia incentivo para a formação profissional. Dentre as principais estratégias de incentivo relatadas indicaram: Acréscimo Salarial, com significância estatística, seguido de Liberação para Formação (ausência justificada do horário de trabalho para algum curso de formação). Por outro lado, 53,2\% não sabiam da existência de um plano de carreira.

Dessa amostra, $61,5 \%$ responderam que realizaram algum curso de formação nos últimos 12 meses - à época em que responderam ao questionário. Na Tabela 1 apresentamos os principais cursos que realizaram nos últimos 12 meses. 


\begin{tabular}{lcc}
\multicolumn{3}{l}{ Tabela I - Frequência das temáticas/conteúdos dos } \\
processos de educação em saúde & & \\
\hline Temática do Curso & Freq. & $\%$ \\
\hline APSUS - Caminhos do Cuidado & 33 & $26 \%$ \\
Agente Comunitário de Saúde & 19 & $15 \%$ \\
Outros cursos complementares & 19 & $15 \%$ \\
Gestão Pública & 10 & $8 \%$ \\
Tratamento de Doença & 6 & $5 \%$ \\
Educação e Saúde & 5 & $4 \%$ \\
Urgências e Emergência & 5 & $4 \%$ \\
Medicina do Trabalho & 4 & $3 \%$ \\
Saúde da Mulher & 4 & $3 \%$ \\
Técnico em Enfermagem & 4 & $3 \%$ \\
Atenção Básica & 3 & $2 \%$ \\
Informática & 3 & $2 \%$ \\
Línguas & 3 & $2 \%$ \\
Medicina Alternativa & 2 & $2 \%$ \\
Pediatria & 2 & $2 \%$ \\
Vigilância em Saúde & 1 & $1 \%$ \\
Área social & 2 & $2 \%$ \\
Medicina Intensiva & 2 & $2 \%$ \\
Odontologia & 1 & $1 \%$ \\
Saúde Baseado em Evidências & 1 & \\
\hline
\end{tabular}

Pelos dados da Tabela 1, ocorreu significância estatística em relação ao curso básico para atuação no SUS promovido pela Secretaria de Saúde do Estado do Paraná, o APSUS, para a Rede de Atenção Psicossocial. Pode-se notar que, em grande maioria, o perfil dos cursos realizados são técnicos, relacionados ao trabalho e menos a uma perspectiva formativa mais ampla.

Passemos agora a apresentar os resultados das entrevistas com os gestores, organizadas segundo os eixos das dificuldades e dos incentivos relacionados à gestão do trabalho e da educação em saúde.

\section{Dificuldades na gestão do trabalho e da educação em saúde, segundo a percepção de secretários municipais de saúde}

Segundo relato dos gestores, para proporcionar a formação ao profissional de saúde, as prefeituras enfrentam várias dificuldades. Uma das situações mais relatadas dizia respeito à condição dos municípios menores que necessitam deslocar seus funcionários para outras cidades para atividades de formação; muitas vezes, por não haver transporte devido à carência de veículos do município (Mo7), acabam priorizando o transporte dos pacientes e não aos funcionários. Também foi mencionado o problema da disponibilidade financeira para custear a ida dos funcionários ao centro formador (M19). Ainda foi citada a dificuldade em coadunar o tempo do trabalho com o tempo para o estudo.

Né, a gente procura dar o apoio e que o que gera depois disso, por exemplo: especialização no meio de semana, vamos dizer assim, em dia de semana, o funcionário tem que se afastar do serviço, então, dois dias no meio de semana é complicado. Então, a dificuldade é essa daí, de você conjugar o serviço com o curso. $O$ ideal é que esses cursos não fossem durante a semana (Mog).

Pode fazer curso, desde que não atrapalhe o fluxo de trabalho (Mo7).

Em função disso, acabam por fazer acertos políticos em relação à carga horária de trabalho semanal. Um município relatou que todos os médicos contratados por concurso para 8 horas diárias tinham acertos com administrações anteriores para diminuição para 6 horas, sendo essa uma condição para se manterem na função. Isso, além do problema jurídico, certamente interfere na atuação profissional e na organização da equipe, pois é um tempo que poderia ser utilizado para formação no trabalho ou fora dele (Mo6).

Outro aspecto apontado dizia respeito aos trâmites internos exigidos pela legislação pública. A Lei n ${ }^{0}$ 8.666 exige a elaboração do processo de licitação para contratação de serviços. Em municípios em que os funcionários do setor não possuem muita experiência, ou que os editais demandem conhecimento mais especializado, a implementação de políticas próprias de qualificação do corpo de profissionais acaba por ser um problema para os gestores.

Essa é a barreira maior, é o jurídico (M17).

Burocracia para executar os cursos (contratação, licitação etc.) (M14). 
Além desses aspectos, também se configura como um problema a rotatividade dos profissionais entre os postos de trabalho, colocando a necessidade de requalificar o profissional, pois a experiência e os conhecimentos acumulados se perdem com a saída do profissional mais experiente. Além do nivelamento dos profissionais da equipe, foi apontado como dificuldade para a gestão a implantação de programas de formação de profissionais de saúde (Mo8, Mog).

Mas, certamente, o problema apontado com maior frequência pelos gestores foi em relação à dimensão individual, de iniciativa e interesse pessoal para buscar a qualificação profissional.

A maior barreira que a gente encontra é na própria iniciativa do funcionário, porque ele desenvolve uma carga horária, a gente até abre mão, por lei, de parte da carga horária, mas normalmente são cursos que abrangem o período noturno, abrange fim de semana (M10).

Ainda, outros gestores afirmam que:

O que eu tenho mais problema mesmo é com funcionário concursado antigo, esse não quer aprender, não quer se atualizar, não quer mudar, mas o pessoal de nivel superior é mais fácil, eles têm essa busca, eles querem. Tem os resistentes, mas às vezes a gente chega lá, fala: "não, vai ter que ir. Vocêvai ter que ir." Eacaba indo. Vai, meio na marra, mas vai. Xingando o secretário, mas vai (Mo6).

Se a gente pudesse qualificar mais os funcionários... Mas tem alguns que nem querem, tem gente que nem gosta... (M19).

tem uns que não ligam para qualificação, para curso, está ali e fica ali, [...] eu estou mandando sempre os mesmos, porque são sempre aqueles que querem fazer, tem outros que não querem nem saber, não vão atrás, é cansativo (M17).

Essa questão merece ser melhor problematizada, pois toda resistência é direcionada a alguma coisa: deve-se à precarização do trabalho? Em função dos salários? Às condições insalubres em que se trabalha no setor saúde? Enfim, é uma questão que não foi respondida pelos gestores e se torna complexa na medida em que em outros contextos a situação foi colocada exatamente em sentido contrário.

Na verdade, cada (Unidade) tem um aspecto diferente da outra. Mas, as pessoas que trabalham lá, todas têm o mesmo pensamento, se qualificar, prestar o melhor atendimento. $\bar{\varepsilon}$ claro que cada um tem uma maneira de agir... (M22).

Tranquilo. Em primeiro lugar porque o pessoal quer participar também (M22).

Não, o pessoal aceitou bem. Os agentes aceitaram bem essas capacitações (Mo1).

Alguns temas importantes foram apontados para serem inseridos no processo de formação dos profissionais: Saúde do trabalhador; tema que precisa ser tratado (Mo1).

Pronto atendimento é ponto crítico em termos de qualificação profissional (Mo5).

Esses aspectos apontados não esgotam toda a questão, mas trazem subsídios para entender o problema da formação em saúde na base do sistema público.

\section{Incentivos na gestão do trabalho e da educação em saúde segundo a percepção de secretários municipais de saúde}

As ações indicadas pelos gestores para a qualificação profissional mostraram-se bastante restritas. Somente o município polo da microrregião possui uma infraestrutura para um processo de formação mais abrangente e organizado; possuem políticas e um Centro de Formação Pedagógica para atender as necessidades da rede. Segundo o secretário municipal de saúde:

tem procurado valorizar o nosso servidor formando para melhor servir a nossa população, que éo nosso 
objetivo fim, mas que também vai agregar a ele a satisfação profissional e a satisfação salarial até em cima dessa questão do Plano de cargos, carreirase salários [...] É permitido aos servidores de carreira terem um ano, um ano e meio de períodos para a sua formação e qualificação profissional (M11).

Alguns municípios optam por buscar empresas privadas para os cursos, e dentre as temáticas procuradas indicaram cursos de motivação (M17, M19, M21). Outro município considerou que a adequação do profissional ao local de trabalho já é uma ação de formação, porque haveria uma melhoria da atuação profissional (M14).

Outros municípios obrigam a participação nos cursos de capacitação, não entrando no mérito o fato de haver ou não incentivo para tal (Mo3), e outros não têm qualquer política ou ação de qualificação dos seus profissionais (M16, M17), contando exclusivamente com o que é ofertado pelo Estado e pela União.

Como ações de iniciativa do município, a maioria indicou a realização de reuniões, seja para discutição dos problemas cotidianos, seja para identificar demandas a serem tratadas nas reuniões mensais (M20).

O que nós temos, assim, como... Lá, nós temos originariamente reuniões todo mês, então, se acaba levantando algumas demandas, o que está acontecendo no serviço acabam sendo levado como pauta para a reunião do mês seguinte (M12).

Uma prática muito frequente é criar os "multiplicadores”: funcionários que realizam os cursos e são responsáveis por "replicar" o conhecimento para os demais colegas (Mo3, Mo5, M18). Podemos afirmar que a maioria dos gestores tem um entendimento de que formar seus funcionários é realizar cursos de capacitação.

No contexto, identificamos duas grandes linhas de atuação para estimular os profissionais a se qualificarem: o incentivo financeiro (Mo2, M11, M12, M14, M16, M2o, M23), ou incentivo logístico (Mo2, Mo3, Mo4, Mo7, Mo9, M19, M2o, M22, M24).

Incentivo financeiro, em geral, está definido nos Planos de Cargos e Salários ou pelo PMAC: avaliação que eu faço dos títulos que ele adquire, [...] todo o ano é feito uma avaliação do desempenho dele e a cada dois anos ele tem uma progressão de acordo comessa avaliação, de acordo com o seu desempenho no trabalho (M16).

recebem uma porcentagem a mais, se eu não me engano, 20\%. Depois que eles fazem o mestrado, 2 ou $5 \%$, uma média que gira isso. [...] avanço financeiro que agregou salarialmente aos nossos servidores todas as suas qualificações profissionais. Então, a partir de agora, e isso está contido no Plano de Cargos, Carreiras e Salários que foi aprovado, todo curso, toda qualificação (M11).

Importante ressaltar que alguns municípios ainda não possuem Plano de Cargos e Salários. Também M12 tem incentivo financeiro mediante avaliação de desempenho analisada por comissão criada por lei, e M2o avaliou que o incentivo financeiro via PMAC, melhorou a qualificação dos profissionais.

Alguns gestores entendem que qualquer incentivo não necessariamente se reverteria em beneficio para o setor público, pois uma melhoria na qualificação colocaria o profissional em melhores condições de buscar outros locais de trabalho na iniciativa privada. Com isso, acabavam por não incentivar, coibiam o profissional para não sair do serviço, argumentando inclusive que havia o uso de tempo/verba pública para financiamento de cursos de interesse particular e privado do profissional.

A gente consulta o jurídico da prefeitura, se eles virem que não tem nenhum problema, que aquele curso vai favorecer mesmo o serviço aqui, que não tem perigo de ele fazer o curso para procurar o serviço fora, eles autorizam e a gente paga (M17).

A postura do gestor ou de uma mentalidade local cria situações em que a formação do profissional parece não ter relação alguma com sua atuação, entende-se que se trata de uma escolha individual, que não faz parte de uma política pública (M1o).

$\mathrm{Na}$ outra via, alguns municípios possuem como política de apoio à qualificação, mais ou menos formalizada, mediante estratégias de apoio logístico: 
incentivo assim, de precisar faltar no serviço, repor carga horária em outro dia, isso a gente faz (Мо3).

O que nós fazemos é liberar os funcionários pra realizar a capacitação pretendida (Mog).

Contudo, em algumas situações, são colocadas condições para o apoio logístico:

Desde que não atrapalhe bruscamente ofluxo. Porque nós somos num município pequeno, a gente conta com poucos profissionais. [...] eu mobilizei a equipe inteira, porque tava sendo disponibilizada uma pós-graduação à distância [...] a questão de transporte, também, a prefeitura sempre ajuda (Mo7).

Em relação ao tipo de formação, a maioria utiliza a estrutura do Estado para ofertar os cursos pelo APSUS, um programa do governo (M1, M2, M5, M6, M8, M10, M13, M14, M15, M16, M21).

Que a gente tem de atualização, que a gente faz com todos os profissionais da atenção básica, éo APSUS, que é o estado inteiro, que é um programa do governo estadual, então, com todos eles a gente faz essa capacitação (Mo3).

Elas tão trazendo coisa boa pra nós, cada vez ajudando mais o (município) a desenvolver (M19).

Segundo os gestores, ainda encontramos situações em que o apadrinhamento político continua sendo critério para definição dos profissionais para realizar qualificação profissional.

quando eu atuava como profissional, não eram todas as pessoas que eram liberadas pra fazer curso de capacitação. Então, assim, tinha uma questão de escolha. Então, eles escolhiam as pessoas que eles iam liberar pra se capacitar. E a questão de fornecer carro também era complicada. Muitas vezes, se eu quisesse ir nas coisas, eu acabava tendo que ir com meu carro, se eu não quisesse ir às 6 horas da manhã, junto com a Van dos pacientes (Mo7).

Encaminhando já para as conclusões, vale a pena destacar uma crença bastante comum entre os gesto- res, de que a formação profissional impacta na qualidade da atenção à saúde, o que fica expresso na afirmação de que esperam que o investimento em qualificação profissional se reflita no serviço prestado à população.

não queremos fazer um benefício apenas para falar que foi agregar salário, nós queremos o elemento palpável, que é a satisfação do usuário, que é a melhoria da produtividade, mas principalmente que é a resolubilidade no processo de trabalho e no atendimento. [...] Então, sempre tem aqueles comparativos, "fulano teve tanto de pontuação, eu fiz mais que ciclano". Então, acho que mais esse tipo de barreiras ou quando tem algum tipo de penalidades. "Você não alcançou os 25\% do (GPD)", aí vem tudo em cima de reclamação (M11).

Entretanto, apesar da crença, a estratégia adotada para que o funcionário busque melhorar sua atuação é majoritariamente pela via do incentivo salarial. Cabe destacar o exemplo de um dos municípios que tem uma política de agregar $25 \%$ ao salário com cursos específicos na área de saúde pública ou de saúde da família, além de gratificação de 10\% por avaliação da comunidade e das equipes gestoras.

Esse mesmo município tem buscado parcerias para trazer opções de formação aos profissionais:

Município que atende os três níveis de atenção, fez parceria com o Conasa e o Conasens, um curso de pós-graduação que foi executado em parceria com o Instituto Sírio Libanês de Ensino e Pesquisa, onde nós oferecemos 40 vagas para cada um dos módulos do curso de auditoria, do curso de preceptoria e o outro era de gestão da rede local de saúde, [...] liberei 70 servidores que acabaram aí, tendo toda essa qualificação profissional (Mı1).

Mas são estratégias de incentivo meritocráticas e vinculadas ao financeiro. Além disso, qualificação deve ser entendida como cursos com conteúdos específicos, sem qualquer relação com o contexto social e econômico, e sem qualquer discussão política sobre a saúde no país e na região.

Quanto à implantação de políticas de longo prazo, a maioria dos municípios não tem plano de carreira específico; somente $10 \%$ dos municípios fez 
menção a esse quesito como forma de incentivar a formação profissional.

O plano de carreira está em andamento (M19).

Não, não encontrei barreiras, e assim que foi idealizado e implementado o plano de carreiras (M16).

Nós temos o Plano de Cargos, Carreira e Salários que foi aprovado no ano passado (M11).

Pelos resultados, podemos inferir que, apesar do SUS ter completado mais de duas décadas, nos municípios brasileiros, os trabalhadores da saúde ainda sofrem com a não regulamentação e valorização do seu trabalho. Reconhecer a importância do profissional de saúde, proporcionando-lhe um plano de carreira, talvez fosse o mínimo para garantir dignidade a essas pessoas.

Os achados da pesquisa nos possibilitaram sintetizar os resultados em torno de uma matriz (Quadro 1) que correlaciona os dois eixos de análise dos resultados (dificuldades $\mathrm{X}$ incentivos para a gestão do trabalho e da educação em saúde) com as seis categorias empíricas: Determinantes políticos e jurídicos da administração pública; Tensão entre a liberação de tempo do trabalho e o tempo necessário para a formação; Incentivos financeiros e valorização na carreira; Dimensão individual subjetiva do profissional de saúde; Acesso à formação: distância geográfica e deslocamento; Demandas por formação a partir do processo de trabalho em equipe.

\section{Quadro I - Matriz de síntese dos resultados: correlação entre difıculdades/incentivos na gestão do trabalho $e$ da educação em saúde e as categorias de conteúdo nas falas}

\begin{tabular}{|c|c|c|}
\hline Eixos/categorias & Dificuldade & Incentivos \\
\hline 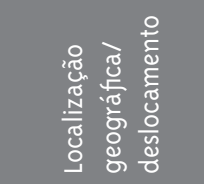 & $\begin{array}{l}\text { - Distância do centro formador, necessidade de } \\
\text { deslocamentos e falta de transporte. }\end{array}$ & $\begin{array}{l}\text { - Disponibilização de transporte e alimentação; } \\
\text { - Cursos de pós-graduação a distância; } \\
\text { - Centro de capacitação pedagógico. }\end{array}$ \\
\hline 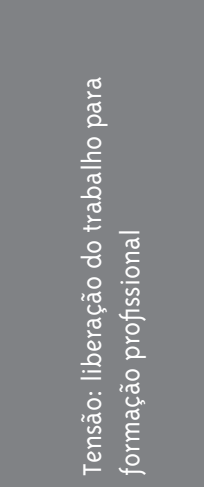 & $\begin{array}{l}\text { - Lei obriga dedicação de tempo de trabalho para } \\
\text { formação; } \\
\text { - Liberação do tempo de trabalho para o estudo, que } \\
\text { atrapalha fluxo do trabalho; } \\
\text { - Acertos informais sobre carga horária; } \\
\text { - Obrigatoriedade de participação nos cursos de } \\
\text { capacitação; } \\
\text { - Poucos cursos durante a semana, e outros são noturnos; } \\
\text { - Falta de critérios para seleção das pessoas liberadas } \\
\text { para formação; } \\
\text { - Prática de formar multiplicadores para "replicar" aos } \\
\text { demais. }\end{array}$ & $\begin{array}{l}\text { - Liberação de períodos de trabalho para a } \\
\text { formação profissional; } \\
\text { - Liberação dos funcionários para fins de } \\
\text { capacitação (Muitas vezes limitado aos de } \\
\text { diploma superior); } \\
\text { - Facilidade na reposição da carga horária de } \\
\text { trabalho. }\end{array}$ \\
\hline 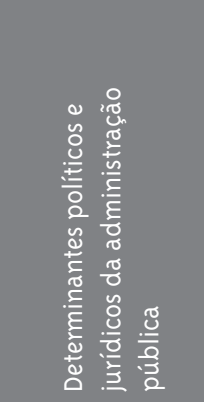 & $\begin{array}{l}\text { - "Burocracia" jurídica - licitação para contratação de } \\
\text { serviços de treinamento e capacitação; } \\
\text { - Decisão política de contratar empresas privadas para } \\
\text { oferta de cursos; } \\
\text { - Falta de investimento financeiro em capacitação dos } \\
\text { profissionais; } \\
\text { - Alta rotatividade dos profissionais nas unidades de } \\
\text { saúde; } \\
\text { - Analise jurídica para coibir o financiamento de cursos } \\
\text { de interesse particular. }\end{array}$ & $\begin{array}{l}\text { - Melhoria da produtividade; } \\
\text { - Resolutividade no processo de trabalho e no } \\
\text { atendimento clínico; } \\
\text { - Maior potencial de satisfação ao usuário } \\
\text { - Avaliações regulares do desempenho profissional } \\
\text { para fins e progressão funcional. }\end{array}$ \\
\hline
\end{tabular}


Quadro I - Continuação

\begin{tabular}{|c|c|c|}
\hline Eixos/categorias & Dificuldade & Incentivos \\
\hline 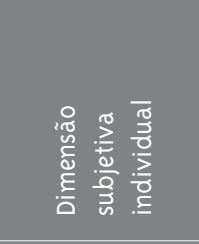 & $\begin{array}{l}\text { - Mobilizar a dimensão subjetiva da iniciativa e do } \\
\text { interesse pessoal; } \\
\text { - Desinteresse dos funcionários para realização de } \\
\text { cursos de formação; } \\
\text { - Resistência de funcionários para realizar cursos. }\end{array}$ & $\begin{array}{l}\text { - Compromisso ético com a população; } \\
\text { - Satisfação e realização profissional; } \\
\text { - "Absorção" de conhecimentos e acúmulo de } \\
\text { certificados com valor para o currículo; } \\
\text { - Interesse dos funcionários em qualificação para } \\
\text { melhor atendimento. }\end{array}$ \\
\hline 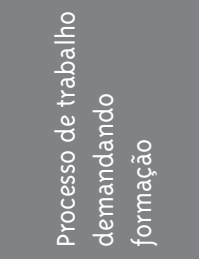 & $\begin{array}{l}\text { - Maior necessidade de formação nos seguintes } \\
\text { temas: saúde do trabalhador; urgência e emergência } \\
\text { (pronto-atendimento); vigilância sanitária. }\end{array}$ & $\begin{array}{l}\text { - Ações próprias das equipes locais: reuniões para } \\
\text { discutir problemas cotidianos do serviço; } \\
\text { - Identificação de demandas locais para discussão } \\
\text { em reuniões mensais; } \\
\text { - Ampliação da oferta de espaços de reflexão sobre } \\
\text { a prática. }\end{array}$ \\
\hline 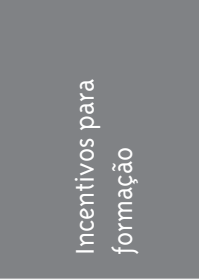 & $\begin{array}{l}\text { - Sem incentivo financeiro agregado ao salário do } \\
\text { profissional; } \\
\text { - Políticas de longo prazo: a maioria dos municípios } \\
\text { não tem plano de carreira para saúde. }\end{array}$ & $\begin{array}{l}\text { - Política de valorização do servidor; } \\
\text { - Incentivo salarial; } \\
\text { - Política de gratificação por qualificação } \\
\text { profissional; } \\
\text { - Plano de Cargos, Carreiras e Salários; } \\
\text { - Estabelecimento de parcerias para ampliar } \\
\text { opções de formação aos profissionais. }\end{array}$ \\
\hline
\end{tabular}

\section{Discussão}

Os dados da pesquisa nos indicaram inicialmente e de maneira bastante contundente que os gestores entendem qualificação profissional como "realização de cursos" e que os saberes para além do domínio técnico não têm importância. Nenhum dos gestores citou ou fez referência à educação permanente na perspectiva crítica dos pesquisadores da área. A impressão que fica é que as discussões teóricas sobre formação permanente, formação em serviço etc. não fazem parte do contexto dos gestores entrevistados. Para além dessa visão reduzida da formação, foi sinalizada uma série de problemas tanto de ordem prática quanto de ordem política envolvendo a educação e o trabalho. De ordem prática, podemos inferir que a distribuição geográfica dos municípios na região com a centralização da capacitação nos municípios maiores se tornou um fator crítico para os profissionais buscarem qualificação profissional. Apesar de existir incentivos, tais como transporte e alimentação, o que mais preponderou foram as dificuldades, seja nos arranjos necessários para garantir o atendimento à população, seja para coadunar a vida privada e a profissional, uma vez que os cursos, em sua maioria, são ofertados aos finais de semana ou à noite.

A reflexão sobre as políticas neoliberais a partir dos conceitos de Ball nos possibilitou compreender o modo como o avanço da lógica neoliberal tem afetado o funcionamento da gestão de recursos humanos e dos processos de formação nas secretarias de saúde, provocando grande sofrimento para os funcionários públicos e se caracterizando como um processo de desprofissionalização do trabalho. Isso gera grandes problemas no cotidiano do trabalhador e afeta de forma negativa a qualidade dos serviços públicos, segundo parâmetros que não sejam os da produtividade e da performance, estabelecidos pela lógica do gerencialismo privado.

Com esse contexto geográfico e político, a tensão entre a liberação para formação e a garantia do atendimento à população mostrou-se bastante significativa. Sobre essa questão, a maneira de resolver foi distinta: alguns com maior flexibilidade, outros nem tanto; alguns municípios com grande interesse, outros nem tanto, demonstrando que se trata mais de uma visão do gestor, vinculado, talvez, pela sua inserção na saúde e no serviço público, e menos por uma política pública de saúde, seja local ou 
regional. Isso pode ser analisado, pois, mesmo nos casos em que houve apoio logístico, não se trata de uma política pública local, mas depende do gestor.

Portanto, é relevante cada papel que se desempenha dentro das secretarias de saúde, ou seja, cada atuação dos atores políticos, que são os secretários de saúde, diretores, coordenadores, profissionais e população. São esses os atores capazes de trazer um conjunto de contextos históricos e dinâmicas psicossociais dentro de uma relação com textos e imperativos que produzem ações e atividades que são políticas e, portanto, contextualizadas (Ball et al., 2013). As estratégias neoliberais, em linhas gerais, têm a pretensão de fazer com que os profissionais pensem, sintam e atuem de acordo com as demandas da instituição, ou seja, elas têm a capacidade de remodelar à sua imagem as organizações que monitoram (Ball, 2005). Entretanto, há resistências, e daí vêm as lutas.

Nos municípios menores, identificamos a prática das reuniões das equipes de trabalho, o que poderíamos entender como uma visão de qualificação mais próxima do conceito de formação permanente; porém esses espaços não eram realizados com esse entendimento, mas sim como fórum para organização das equipes e outras discussões mais pontuais envolvendo campanhas e mobilização da comunidade. A maioria dos gestores se limita a oferecer aos seus funcionários cursos de cunho técnico, vinculados às políticas estaduais, desconectados dos determinantes sociais da saúde e de uma formação crítica e reflexiva. Com isso, consideramos que a prioridade da gestão na região ainda é uma formação técnica individual dos profissionais, o que já se mostrou com baixo potencial de impacto no trabalho das equipes no cotidiano dos serviços de saúde.

Cada vez mais sentimos a perda da capacidade de diálogo. Muito sofrimento tem sido produzido e isso deteriora as relações interpessoais, aumentando o individualismo e prejudicando o caráter coletivo da saúde pública. Cada vez mais temos observado práticas verticais, centralizadoras e autoritárias sendo praticadas não só por gestores dos níveis centrais, mas também pela direção e coordenação das unidades de saúde que, pressionadas por atingir resultados, mas sem condições de trabalho para fazerem isso, acabam por tencionar as relações de trabalho e estabelecer um sistema de controle cruel que vem deteriorando a prática profissional e o trabalho em saúde na esfera pública.

A individualidade dos profissionais também aparece nesse contexto, ora pelo entendimento de que o incentivo para a qualificação está relacionado a um compromisso com a coletividade, ora tratado como impedimento para que o funcionário busque sua qualificação; pois, segundo alguns gestores, não há por parte deles interesse em sua qualificação, em geral daqueles com mais tempo na carreira pública.

Em relação à política local, foi apontado que a burocracia jurídica é um dos fatores que dificultam a implantação de ações de qualificação profissional, e isso aliado a questões políticas gera um contexto de maior complexidade e dificuldade para viabilizar a qualificação profissional de suas equipes.

A questão da vinculação da qualificação com o processo de trabalho foi muito pouco abordada pelos gestores. Na concepção deles, qualificação é a realização de cursos em qualquer modalidade. Nenhum dos gestores abordou diretamente a formação em serviço, sequer entendiam os espaços das reuniões das equipes como espaços de formação. Os municípios que realizam tal prática (reuniões com a equipe) são, em geral, os pequenos e com menor número de equipes. Nesse sentido, talvez possamos inferir que a maior proximidade geográfica e de relações possa ser um fator que estimule os processos de formação em serviço com centralidade no processo de trabalho na perspectiva apontada pela literatura.

Em relação aos incentivos para a qualificação profissional, ainda são poucos os municípios que possuem políticas claras, com critérios estabelecidos em lei. Aqueles que as possuem, os incentivos são financeiros, de acréscimos salariais em função da realização de processos ou programas de qualificação profissional, com ganhos baseados na meritocracia e/ou na avaliação da população. Com isso, a realidade está distante da discussão sobre formação crítica, como crítica à lógica meritocrata neoliberal e fundamentada na reflexão crítica e coletiva das necessidades de formação e desenvolvimento a partir das práticas cotidianas; não só um treinamento para aprofundar conteúdos teóricos, mas ações práticas para se formar enquanto sujeito histórico e agente de transformação da realidade social (Bertoldo; Mo- 
reira; Jimenez, 2012; Mészáros, 2008). Concordando com essa concepção filosófica, não a verificamos na prática. Isso evidencia a necessidade de se pensar ações educativas que promovam o pensamento crítico para os próprios gestores de saúde.

Frente a esses desafios, muitos gestores optam por se isolar ou adotar uma atitude um tanto alienada, baseada no discurso daqueles que fingem querer a real melhora do sistema público brasileiro, mas que na verdade estão preocupados com seus interesses individuais ou em estabelecer convênios suspeitos com empresas privadas. Está claro que não fazem propriamente uma decisão consciente no sentido de contribuir para a precarização da saúde pública, mas, muitas vezes, são constrangidos e ameaçados e acabam por reproduzir nas secretarias de saúde um sistema de trabalho pouco colaborativo, não democrático e centralizador. Por outro lado, também é verdade que muitos profissionais de saúde, já desanimados com o contexto contemporâneo e incapazes de perceber uma saída a curto prazo, acabam por desistir de se engajar nas lutas e nos movimentos de resistência, assumindo unicamente uma postura de aparente descaso ou descompromisso como forma de se proteger enquanto indivíduos de todo sofrimento e angústia que o sistema gerencial vem promovendo.

Via de regra, entende-se formação/qualificação/ educação profissional como cursos com conteúdos tradicionais relacionados aos assuntos emergenciais da comunidade: dengue, aids etc. Com isso, finalizamos este artigo indicando as principais limitações encontradas e novas possibilidades de pesquisa e aprofundamento.

Uma das limitações foi o perfil dos gestores, alguns muito recentes na função, o que não permitiu maior desenvolvimento em certos temas, em especial aqueles relacionados à formação. Consideramos pertinente aprofundar na relação entre interesse/ desinteresse de formação versus tempo de trabalho com os funcionários, de maneira que se possa melhor dimensionar essa relação em contextos urbanos de distintos portes. Também seria oportuno investigar as estratégias informais utilizadas pelos coletivos para analisar como essas experiências podem ser consideradas educação em saúde.
É possível perceber que o golpe de Estado no Brasil iniciado em 2016 tem promovido o desânimo, como a descrença na política. Por outro lado, percebemos que esses movimentos não estão acontecendo somente no Brasil, mas representam uma nova fase da política neoliberal, que ao perceber as crescentes manifestações contrárias às políticas que promovem acumulação de poder e renda, tem agido violentamente no sentido de reprimir os movimentos sociais e de resistência.

Por fim, nossos resultados permitem afirmar que, na percepção dos secretários municipais de saúde, as principais dificuldades para a implementação de ações educativas são: a logística tempo/ espaço para articular trabalho e formação, a falta de interesse dos trabalhadores, determinantes externos de natureza política/jurídica. Dentre os incentivos para a formação dos profissionais, surge majoritariamente a questão financeira, o que é preocupante em momentos de crise econômica, pois pode revelar uma paralisia nas práticas de formação profissional. É preciso considerar, ainda, a existência de uma enorme lacuna entre o debate teórico no campo da educação em saúde e a discrepante realidade encontrada nesses municípios. Por fim, conclui-se indicando que, apesar de haver um consenso da importância da educação em saúde para a qualidade da atenção e a organização do processo de trabalho nos serviços de saúde, existe ainda um longo caminho a ser percorrido para aprimorar a gestão pública dessas ações no Sistema Único de Saúde.

\section{Referências}

ANGUERA, M. T. Posición de la metodología observacional en el debate entre las opciones metodológicas cualitativa y cuantitativa: ¿enfrentamiento, complementariedad, integración? Psicologia em Revista, Belo Horizonte, v. 10, n. 15, p. 13-27, 2004.

ANGUERA, M. T. Metodología cualitativa y cuantitativa. In: IZQUIERDO, C.; PERINAT, A. (Coord.). Investigar en psicología de la comunicación: nuevas perspectivas conceptuales y metodológicas.

Barcelona: Amentia, 2010. p. 211-232. 
BALL, S. J. Diretrizes políticas globais e relações políticas locais em educação. Currículo sem Fronteiras, [s. l.], v. 1, n. 2, p. 99-116, 2001.

BALL, S. J. Profissionalismo, gerencialismo e performatividade. Cadernos de Pesquisa, São Paulo, v. 35, n. 126, p. 539-564, 2005.

BALL, S. J.; MAGUIRE, M.; BRAUN, A. How schools do policy: policy enactments in secondary schools. London: Routledge, 2012.

BALL, S. J. et al. A constituição da subjetividade docente no Brasil: um contexto global. Revista Educação em Questão, Natal, v. 46, n. 32, p. 9-36, 2013.

BARDIN, L. Análise de conteúdo. Lisboa: Edições 7O, 1977 .

BERTOLDO, E.; MOREIRA, L. A. L.; JIMENEZ, S. (Org.). Trabalho, educação e formação humana frente à necessidade histórica da revolução. São Paulo: Instituto Lukács, 2012.

CAMPOS, G. W. S.; CUNHA, G. T.; FIGUEIREDO, M. D. Práxis e formação Paideia: apoio e cogestão em saúde. São Paulo: Hucitec, 2013.

CARVALHO, R. A. Análise do processo de desenvolvimento de cursos a distância no contexto da Universidade Aberta do Sistema Único de Saúde. 2016. Dissertação (Doutorado em Educação em Ciências e Saúde) - Universidade Federal do Rio de Janeiro, Rio de Janeiro, 2016.

CASOTTI, E. Odontologia no Brasil: uma (breve) história do pensamento sobre o ensino. 2009. Dissertação (Doutorado em Educação em Ciências e Saúde) - Universidade Federal do Rio de Janeiro, Rio de Janeiro, 2009.

FIGUEIREDO, G. O.; BRITO, D. T. S.; BOTAZZO, C. Ideologia, fetiche e utopia na saúde: uma análise a partir da saúde bucal. Ciência \& Saúde Coletiva, Rio de Janeiro, v. 8, n. 3, p. 753-763, 2003. Disponível em: <https://goo.gl/qo7Hiq>. Acesso em: 15 maio 2010.

FREIRE, P. Política e Educação. São Paulo: Paz e Terra, 2014.
GADOTTI, M. Educação e poder: introdução à pedagogia do conflito. São Paulo: Cortez, 2012.

GIROUX, H. Teoria crítica e resistência em educação: para além das teorias de reprodução. Petrópolis: Vozes, 1986.

MÉSZÁROS, I. Educação para além do capital. São Paulo: Boitempo, 2008.

PORTILLO, J. A. C.; BELACIANO, M. I. Contribuição com vinte elementos teóricometodológicos constituídos em função de um novo paradigma da saúde e educação. Divulgação em Saúde para Debate, Rio de Janeiro, v. 9, p. 2732, ago. 1994.

ROVERE, M. R. Gestión estratégica de la educación permanente en salud. In: HADDAD, J. Q.; ROSCHKE, M. A. C.; DAVINI, M. C. Educación permanente de personal de salud. Washington, DC: OPS, 1994. p. 63-106. (OPS. Serie de Desarrollo de Recursos Humanos, n. 100)

SAMPIERI, R. H.; COLLADO, C. F.; LUCIO, M. P. B. Metodologia de pesquisa. 3. ed. São Paulo: McGraw-Hill, 2006.

SCHEFFER, M. (Org.). Demografia médica no Brasil 2015. São Paulo: Faculdade de Medicina da USP, 2015 .

TEIXEIRA, C. F.; PAIM, J. S. Políticas de formação de recursos humanos em saúde: conjuntura atual e perspectivas. Divulgação em Saúde para Debate, Rio de Janeiro, v. 12, p. 19-23, jul. 1996.

\section{Contribuição dos autores}

Vermelho trabalhou no tratamento e análise dos dados e na elaboração do texto. Figueiredo participou da análise dos dados e elaboração do texto e realizou a revisão final.

Recebido: 08/07/2016

Reapresentado: 05/04/2017

Aprovado: 11/04/2017 